\title{
AIDS-Related Hodgkin Lymphoma
}

National Cancer Institute

\section{Source}

National Cancer Institute. AIDS-Related Hodgkin Lymphoma. NCI Thesaurus. Code C9279.

Hodg kin lymphoma secondary to AIDS. An increased incidence of Hodgkin lymphomas has been observed in HIV positive patients. Most cases are morphologically classified as lymphocyte depleted or mixed cellularity Hodg kin lymphomas. 